\title{
Transcriptional status of mouse oocytes corresponds with their ability to generate $\mathrm{Ca}^{2+}$ release
}

\author{
Monika Fluks , Katarzyna Szczepanska, Takao Ishikawa² and Anna Ajduk \\ ${ }^{1}$ Department of Embryology, Faculty of Biology, University of Warsaw, Warsaw, Poland and ${ }^{2}$ Department of \\ Molecular Biology, Faculty of Biology, University of Warsaw, Warsaw, Poland \\ Correspondence should be addressed to A Ajduk; Email: aajduk@biol.uw.edu.pl
}

\begin{abstract}
In fully grown ovarian follicles both transcriptionally active (NSN) and inactive (SN) oocytes are present. NSN oocytes have been shown to display lower developmental potential. It is possible that oocytes that have not completed transcription before meiosis resumption accumulate less RNA and proteins required for their further development, including those responsible for regulation of $\mathrm{Ca}^{2+}$ homeostasis. Oscillations of the cytoplasmic concentration of free $\mathrm{Ca}^{2+}$ ions $\left(\left[\mathrm{Ca}^{2+}\right]_{\mathrm{i}}\right)$ are triggered in oocytes by a fertilizing spermatozoon and are crucial for inducing and regulating further embryonic development. We showed that NSN-derived oocytes express less inositol 1,4,5-triphosphate receptor type 1 (IP3R1), store less $\mathrm{Ca}^{2+}$ ions and generate weaker spontaneous $\left[\mathrm{Ca}^{2+}\right]_{i}$ oscillations during maturation than SN oocytes. Consequently, NSN oocytes display aberrant $\left[\mathrm{Ca}^{2+}\right]_{\mathrm{i}}$ oscillations at fertilization. We speculate that this defective regulation of $\mathrm{Ca}^{2+}$ homeostasis might be one of the factors responsible for the lower developmental potential of NSN oocytes.

Reproduction (2019) 157 465-474
\end{abstract}

\section{Introduction}

In all animal species, including mammals, oocytes arrested in prophase of the 1st meiotic division (hereinafter called germinal vesicle (GV) oocytes) undergo an intense growth and accumulate organelles, proteins and mRNAs required for their further functioning (reviewed in Masui 1985, Gilchrist et al. 2008). In mice, pre-antral ovarian follicles contain mainly transcriptionally active oocytes (Mattson \& Albertini 1990, Debey et al. 1993, Zuccotti et al. 1995), whereas oocytes that ceased transcription are present only in antral follicles (Wickramasinghe et al. 1991). However, in such fully grown follicles transcriptionally active oocytes can be observed as well (Liu \& Aoki 2002).

Nuclei of oocytes that completed their growth-related transcription are characterized by a tightly condensed chromatin forming a ring around the nucleolus (so called surrounded nucleolus (SN) oocytes). Oocytes that still transcribe can be distinguished by an amorphous, decondensed chromatin; these are called nonsurrounded nucleolus (NSN) oocytes (Bouniol-Baly et al. 1999; reviewed in Tan et al. 2009). Greater chromatin condensation in SN than in NSN oocytes, however, does not correlate with a decreased histone acetylation. On the contrary, $\mathrm{H} 4 \mathrm{~K} 5$ and $\mathrm{H} 4 \mathrm{~K} 12$ acetylation level is higher in $\mathrm{SN}$ compared to NSN oocytes. Albeit, the methylation level of histones (H3K9) and DNA (5-MeC) is also higher in $\mathrm{SN}$ oocytes than in NSN oocytes (Kageyama et al. 2007).
Transcriptionally active NSN oocytes (NSN-GV) can undergo in vitro meiotic maturation without terminating transcription first (Debey et al. 1993); however, GV oocytes with distinct chromatin configurations (SN-GV and NSN-GV) differ in their ability to undergo the first meiotic division, respond to fertilization or undergo further embryonic development. NSN-GV oocytes resume meiosis during in vitro culture less often than $\mathrm{SN}-\mathrm{GV}$ oocytes. If they do, their meiotic maturation progresses slower and less frequently results in the first meiotic division (Wickramasinghe et al. 1991, Debey et al. 1993, Liu \& Aoki 2002). Moreover, when fertilized, oocytes in metaphase of the 2nd meiotic division (MII) derived from NSN-GVs (NSN-MII oocytes) have lower developmental potential as compared to MII oocytes derived from SN-GVs (SN-MII oocytes). When cultured in vitro, embryos originating from NSN oocytes arrest usually at the 2-cell stage, while $\mathrm{SN}$-derived embryos continue to the blastocyst stage (Zuccotti et al. 2002, Inoue et al. 2008). We hypothesize that hindered $\mathrm{Ca}^{2+}$ homeostasis caused by prematurely terminated transcription and, in consequence, incomplete accumulation of mRNAs encoding proteins key for this process, might be one of the reasons for the lower developmental capabilities of NSN oocytes.

Proper regulation of $\mathrm{Ca}^{2+}$ homeostasis is crucial for embryo development. In mammals, including mice, fertilization induces in oocyte oscillations in cytoplasmic concentration of free $\mathrm{Ca}^{2+}$ ions $\left(\left[\mathrm{Ca}^{2+}\right]_{\mathrm{i}}\right.$; 
Parrington et al. 1996, Saunders et al. 2002; reviewed in Swann \& Lai 2013), which trigger a series of processes essential for the initiation of the embryonic development, such as establishment of the block to polyspermy and completion of the 2 nd meiotic division, and regulate mitochondrial functionality, recruitment of maternal mRNAs and embryonic gene expression (Dumollard et al. 2004, Ozil et al. 2005, Campbell \& Swann 2006, Madgwick et al. 2006, Ozil et al. 2006, Shoji et al. 2006, Tóth et al. 2006, Burkart et al. 2012; reviewed in Ducibella et al. 2006). $\left[\mathrm{Ca}^{2+}\right]_{i}$ oscillations are triggered by a sperm-specific phospholipase C zeta (PLCz) (Saunders et al. 2002). PLCz hydrolyses phosphatidylinositol 4,5-bisphosphate $\left(\mathrm{PIP}_{2}\right)$ to diacylglycerol (DAG) and inositol 1,4,5-triphosphate $\left(\mathrm{IP}_{3}\right)$, which binds to its type 1 receptor, IP3R1, localized in the endoplasmic reticulum (ER). This stimulates $\mathrm{Ca}^{2+}$ channels to open and $\mathrm{Ca}^{2+}$ ions are released from the ER into the cytoplasm. When $\left[\mathrm{Ca}^{2+}\right]_{i}$ rises above a certain threshold, $\mathrm{Ca}^{2+}$ channels close and $\mathrm{Ca}^{2+}$ ions are pumped back to the ER by the ATPdependent pump SERCA. This in turn decreases $\left[\mathrm{Ca}^{2+}\right]_{\mathrm{i}}$ and IP3R1 channels can open again (Corbett et al. 1999, Li \& Camacho 2004; reviewed in Berridge et al. 2003, Ajduk et al. 2008). The oscillations last until the pronuclei are formed (Marangos et al. 2003, Larman et al. 2004, Yoda et al. 2004). $\left[\mathrm{Ca}^{2+}\right]_{i}$ oscillations are also observed during meiotic maturation of mouse oocytes, when they are a response to $\mathrm{IP}_{3}$ produced during the metabolism of phosphatidylinositol (Carroll \& Swann 1992, Carroll et al. 1994).

In the present paper, we show that NSN oocytes display defective $\mathrm{Ca}^{2+}$ homeostasis, that is, store less $\mathrm{Ca}^{2+}$ ions, express lower amount of IP3R1 protein and display weaker spontaneous $\left[\mathrm{Ca}^{2+}\right]_{i}$ oscillations during in vitro maturation than $\mathrm{SN}$ oocytes. In consequence, fertilized NSN-derived MII oocytes generate aberrant $\left[\mathrm{Ca}^{2+}\right]_{\mathrm{i}}$ oscillations consisting of few $\left[\mathrm{Ca}^{2+}\right]_{\mathrm{i}}$ transients of low amplitude and lasting only for approx. $20 \mathrm{~min}$. As $\left[\mathrm{Ca}^{2+}\right]_{i}$ oscillations are important for initiating the embryonic development, inadequate $\mathrm{Ca}^{2+}$ homeostasis may be one of the factors causing lower developmental potential of NSN oocytes.

\section{Materials and methods}

\section{Animals and reagents}

GV oocytes were obtained from 1.5- to 3.5-month-old unprimed F1 (C57Bl6/Tar $\times$ CBA/Tar) mice. Sperm was obtained from 3- to 10-month-old males of the same breed. Animals were maintained in the animal facility of the Faculty of Biology, University of Warsaw at 14:10 light/darkness cycle and provided with food and water ad libitum. Animals were killed by a cervical dislocation. All experiments were performed in compliance with the national regulations: as animals used in the experiments were not injected with hormones before culling, a specific permission from the local ethical committee was not required. If not stated otherwise, reagents were purchased from SigmaAldrich Poland.

\section{Isolation of GV oocytes and in vitro maturation}

Fully grown GV oocytes were released from ovarian antral follicles by puncturing with a needle into M2 medium (M16 medium buffered with HEPES) (Fulton \& Whittingham 1978) with $3^{\prime}, 5^{\prime}$-cyclic adenosine monophosphate (dbcAMP, $150 \mu \mathrm{g} /$ $\mathrm{mL}$ ). Oocytes were separated from the cumulus cells by gentle pipetting. In order to distinguish SN and NSN oocytes, their DNA was stained with Hoechst $33342(100 \mathrm{ng} / \mathrm{mL}$ in M2 supplemented with dbcAMP) for $30 \mathrm{~min}$ in $37.5^{\circ} \mathrm{C}$ and the chromatin configuration was assessed with fluorescence microscopy (Zeiss AxioObserver Z1). Oocytes with dispersed chromatin were identified as NSN oocytes, whereas those with chromatin condensed in a ring around the nucleolus - as SN oocytes (Fig. 1A). Oocytes with a transitional chromatin morphology, with features of both SN and NSN oocytes, were excluded from further experiments. In vitro maturation, if required, was performed for 15-16 h in M16 medium in $37.5^{\circ} \mathrm{C}$ and in $5 \% \mathrm{CO}_{2}$ in the air.

\section{Time lapse-imaging of $\left[\mathrm{Ca}^{2+}\right]_{i}$ in oocytes}

Oocytes were incubated for $30 \mathrm{~min}$ in M2 medium with $5 \mu \mathrm{M}$ fluorescent $\mathrm{Ca}^{2+}$ indicator Oregon Green 488 BAPTA$1 \mathrm{AM}$ (Molecular Probes, Thermo Fisher Scientific) in $37.5^{\circ} \mathrm{C}$. For imaging, oocytes were transferred to a glass-bottom dish (MatTek Corporations) on the time-lapse imaging system (Zeiss Axiovert microscope equipped with AxioCam HRm camera and an environmental chamber) and then either in vitro matured (in M16 medium), fertilized (in M2 medium without bovine serum albumin (BSA)) or treated with thapsigargin $\left(10 \mu \mathrm{M}\right.$ in $\mathrm{M} 2$ without $\mathrm{Ca}^{2+}$ and $\left.\mathrm{Mg}^{2+}\right)$ or $\mathrm{A} 23187$ ionophore $\left(1 \mu \mathrm{M}\right.$ in $\mathrm{M} 2$ without $\mathrm{Ca}^{2+}$ and $\left.\mathrm{Mg}^{2+}\right)$. Single-plane images were taken every $10 \mathrm{~s}$. Oocytes were illuminated with $488 \mathrm{~nm}$ light, and the emitted light was collected with eGFP filter. Changes in $\left[\mathrm{Ca}^{2+}\right]_{i}$ were assessed by measuring mean intensity of Oregon Green 488 BAPTA fluorescence in time. In order to avoid any additional variability between experiments caused by a different extent of dye loading, the initial (prefertilization or pre-treatment) mean intensity of fluorescence was calculated for each oocyte and then used to standardize the measurements in this oocyte. Therefore, the values we present are ratios: measured fluorescence intensity/initial fluorescence intensity.

\section{In vitro fertilization}

Sperm was extracted from epididymes into $500 \mu \mathrm{L}$ of fertilization medium (Fraser 1982) with BSA $(5 \mathrm{mg} / \mathrm{mL})$ and incubated $1.5-2 \mathrm{~h}$ in $37.5^{\circ} \mathrm{C}$ and $5 \% \mathrm{CO}_{2}$ in the air in order to undergo capacitation. MII oocytes loaded with Oregon Green 488 BAPTA-1AM were subjected to acidic Tyrode's solution $(\mathrm{pH} 2.5$; Fulton \& Whittingham 1978) in order to remove zonae pellucidae. Denuded oocytes were transferred to M2 without BSA in a glass-bottom dish (MatTek Corporations) and 

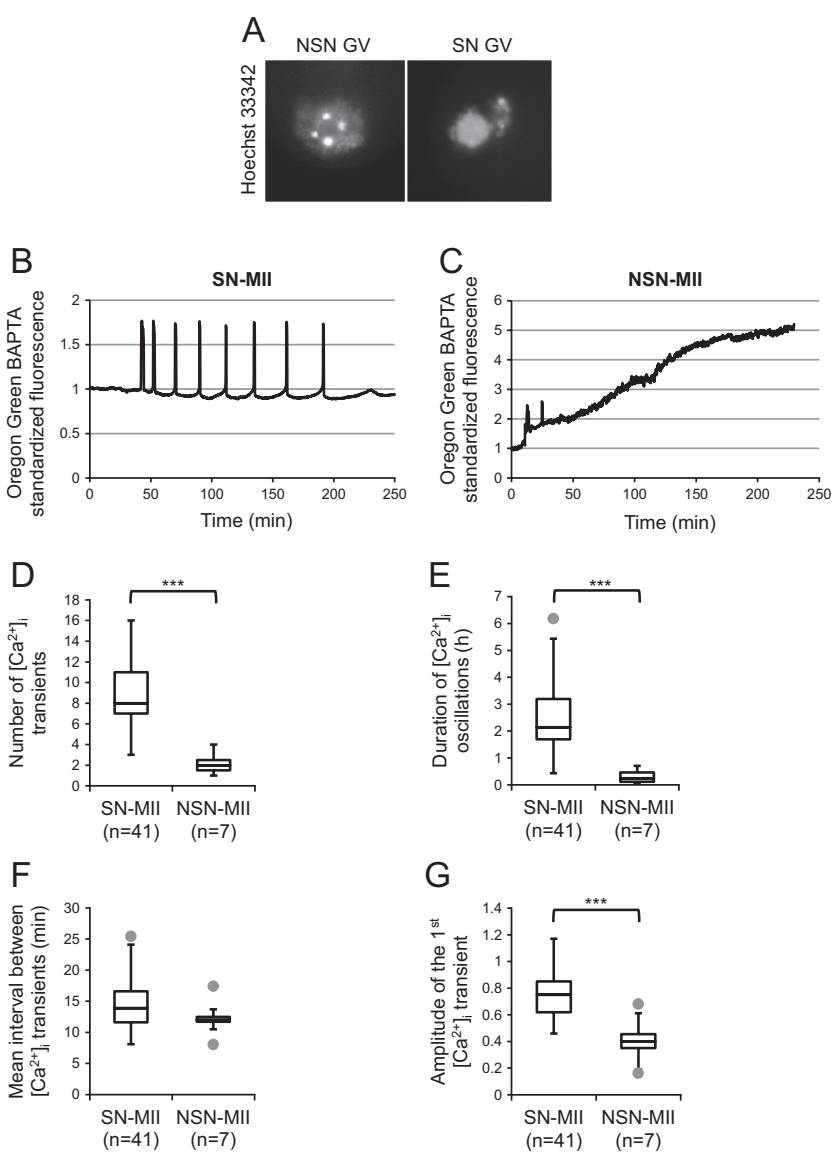

Figure $1\left[\mathrm{Ca}^{2+}\right]_{i}$ oscillations in fertilized $\mathrm{SN}$ - and NSN-derived MII oocytes. (A) A representative Hoechst 33342 staining of NSN- and $\mathrm{SN}-\mathrm{GV}$ nuclei. (B and C) Representative patterns of fertilizationinduced $\left[\mathrm{Ca}^{2+}\right]_{i}$ oscillations in $\mathrm{SN}-(\mathrm{B})$ and NSN-derived MII oocytes (C). (D) Number of $\left[\mathrm{Ca}^{2+}\right]_{\mathrm{i}}$ transients, (E) duration of $\left[\mathrm{Ca}^{2+}\right]_{\mathrm{i}}$ oscillations, (F) mean interval between $\left[\mathrm{Ca}^{2+}\right]_{i}$ transients in the first hour of $\left[\mathrm{Ca}^{2+}\right]_{i}$ oscillation and $(\mathrm{G})$ amplitude of the first $\left[\mathrm{Ca}^{2+}\right]_{i}$ transient in fertilized SN- and NSN-derived MII oocytes. Graphs (D, $\mathrm{E}, \mathrm{F}$ and $\mathrm{G}$ ) present median and the first and the third quartile values. The ends of the whisker are set at $1.5 \times \mathrm{IQR}$ above the third quartile and $1.5 \times \mathrm{IQR}$ below the first quartile. Dots show the minimum and maximum values if they are outside the range (outliers). ${ }^{* * *} P<0.001$.

allowed to stick to the glass bottom. 1-2 $\mu \mathrm{L}$ of capacitated sperm suspension was added to the oocytes. Time-lapse imaging was performed as described above for $4-5 \mathrm{~h}$.

\section{Real time RT-PCR}

MII oocytes were transferred in groups of five into $10 \mu \mathrm{L}$ of Lysis/Binding Buffer (Dynabeads mRNA DIRECT Micro Kit, Thermo Fisher Scientific) and stored in $-80^{\circ} \mathrm{C}$ until further analysis. mRNA was isolated from pooled samples of 15-20 oocytes using the Dynabeads mRNA DIRECT Micro Kit (Thermo Fisher Scientific) according to the manufacturer's protocol. In short, thawed samples were rotated with $10 \mu \mathrm{L}$ of paramagnetic oligo- $(\mathrm{dT})_{25}$ bead suspension for $30 \mathrm{~min}$ at room temperature. mRNA was eluted from the beads by adding $10 \mu \mathrm{L}$ of DEPC-treated water and heated for $10 \mathrm{~min}$ at $70^{\circ} \mathrm{C}$ with $0.5 \mu \mathrm{g}$ oligo $(\mathrm{dT})_{25}$. The reverse transcription was performed in total volume of $20 \mu \mathrm{L}$ using $200 \mathrm{U}$ of Superscript II Reverse Transcriptase, $0.5 \mathrm{mM}$ dNTPs and $40 \mathrm{U}$ RNase inhibitor (Invitrogen, Thermo Fisher Scientific) at $42^{\circ} \mathrm{C}$ for $50 \mathrm{~min}$. Synthesized cDNA was diluted twice with nucleasefree water (Thermo Fisher Scientific) and subjected to realtime PCR using TaqMan Gene Expression MasterMix and TaqMan Gene Expression Assays probes (Itpr1/IP3R1: cat. no. Mm00439907_m1; Atp2a2/SERCA2: Mm01275320_ m1; Actb/Actin B: Mm01205647_g1) (Applied Biosystems, Thermo Fisher Scientific) in StepOne Real-Time PCR System thermocycler (Applied Biosystems, Thermo Fisher Scientific; $50^{\circ} \mathrm{C} / 2 \mathrm{~min} ; 60^{\circ} \mathrm{C} / 10 \mathrm{~min}$; 50 cycles: $95^{\circ} \mathrm{C} / 15 \mathrm{~s}, 60^{\circ} \mathrm{C} / 1 \mathrm{~min}$ ). Relative level of expression was evaluated using $2^{-\Delta C t}$ method (Livak \& Schmittgen 2001), where actin B was used for normalization.

\section{Western blot}

The level of IP3R1 protein was examined in samples of 50 oocytes. Cell lysates were mixed with $4 \times$ NuPage LDS sample Buffer and 10× NuPage Sample Reducing Agent (Invitrogen, Thermo Fisher Scientific) and were heated for $10 \mathrm{~min}$ in $70^{\circ} \mathrm{C}$. The samples were subjected to electrophoresis in NuPage Novex 3-8\% Tris-Acetate gels (Invitrogen, Thermo Fisher Scientific) and separated proteins were transferred onto PVDF membranes (Hyperbond-P, Amersham Biosciences), which were probed with a rabbit polyclonal antibody (Rbt03) raised against a 15 amino acid peptide sequence of the C-terminal end of the IP3R1 (Parys et al. 1995) and mouse monoclonal antibody against HSP90 (Origene) diluted 1:500 and 1:1000 respectively in 5\% non-fat milk in TTBS. Blotted proteins were incubated with primary antibodies for $1 \mathrm{~h}$. A goat antirabbit (Pierce, Thermo Fisher Scientific or Bio-Rad) and goat anti-mouse (Bio-Rad) antibodies conjugated with horseradish peroxidase diluted 1:7000 and 1:10,000, respectively, were used as secondary antibodies in 1-h incubation. Detection was performed by the enhanced chemiluminescence technique using SuperSignal West Dura Extended Duration Substrate reagents (Pierce, Thermo Fisher Scientific) according to manufacturer's instruction.

\section{Statistical analysis}

Statistical analysis involved $\chi^{2}$ test, the non-parametric MannWhitney test ( $U$-test) and the Kruskal-Wallis ANOVA test. The differences between groups were considered statistically significant for $P<0.05$. Values in the text show means \pm standard deviation, but graphs display medians and quartiles.

\section{Results}

Among the GV oocytes collected from unprimed females $59.5 \%(263 / 442)$ comprised the SN oocytes and $40.5 \%(179 / 442)-N S N$ oocytes $(P<0.01)$. During in vitro maturation, $92.0 \%(242 / 263)$ of SN oocytes resumed meiosis (i.e. underwent germinal vesicle breakdown, GVBD) and 82.1\% (216/263) reached 
MII stage. Among the NSN oocytes $69.3 \%(124 / 179)$ underwent GVBD and 42.5\% (76/179) reached MII stage. To summarize, $\mathrm{SN}$ oocytes more frequently went through GVBD and reached MII stage compared to NSN oocytes $(P<<0.0001)$, which accords with the previous data (Wickramasinghe et al. 1991, Debey et al. 1993, Zuccotti et al. 1995, Liu \& Aoki 2002).

As in some experiments oocytes were filmed during in vitro maturation, we were able to calculate mean timings of the main maturation events. GVBD occurred on average after $2.06 \pm 2.01 \mathrm{~h}$ in $\mathrm{SN}$ oocytes $(n=76)$ and after $5.22 \pm 3.74 \mathrm{~h}$ in NSN oocytes $(n=47$; $P<<0.0001)$. 1st meiotic division could be observed after $11.79 \pm 1.25 \mathrm{~h}$ in $\mathrm{SN}(n=48)$ and $13.79 \pm 1.58 \mathrm{~h}$ in NSN oocytes $(n=10 ; \quad P<0.01)$. Therefore, transcriptionally active GV oocytes resumed meiosis and divided later compared to those transcriptionally inactive, which is consistent with the literature data (Wickramasinghe et al. 1991, Debey et al. 1993, Liu \& Aoki 2002).

\section{Fertilization-induced $\left[\mathrm{Ca}^{2+}\right]_{i}$ oscillations differ between oocytes with NSN or SN origin}

In order to assess whether oocytes' transcriptional status at the beginning of meiotic maturation alters their ability to maintain $\mathrm{Ca}^{2+}$ homeostasis, we examined $\left[\mathrm{Ca}^{2+}\right]_{i}$ oscillations generated in MII oocytes of the NSN or SN origin in response to fertilization. To this end, SN-GV (transcriptionally inactive) and NSN-GV (transcriptionally active) oocytes were matured in vitro to MII stage (SN-MII and NSN-MII respectively), loaded with Oregon Green 488 BAPTA-1AM dye, fertilized and filmed using a time-lapse technique.

Sperm-induced $\left[\mathrm{Ca}^{2+}\right]_{\mathrm{i}}$ oscillations in SN-MII oocytes $(n=41$; Fig. 1B) lasted for $2.52 \pm 1.33 \mathrm{~h}$ and consisted of $8.6 \pm 3.0\left[\mathrm{Ca}^{2+}\right]_{i}$ transients. $\left[\mathrm{Ca}^{2+}\right]_{i}$ transients occurred every $14.6 \pm 3.8 \mathrm{~min}$ in the first hour. (As frequency of $\left[\mathrm{Ca}^{2+}\right]_{i}$ oscillations changes with time, which may affect the analysis result, we calculated the mean inter-transient interval only for the first hour of $\left[\mathrm{Ca}^{2+}\right]_{i}$ oscillations.) Amplitude of the first $\left[\mathrm{Ca}^{2+}\right]_{i}$ transient was $0.74 \pm 0.17$ (Fig. 1D, E, F and G).

On the other hand, $\left[\mathrm{Ca}^{2+}\right]_{i}$ oscillations in NSN-MII oocytes $(n=7)$ differed vastly from those observed in SN-MII oocytes (Fig. 1C): they lasted for a much shorter time $(18.4 \pm 15.9 \mathrm{~min}, P<0.0001)$ with just $2.1 \pm 1.1$ $\left[\mathrm{Ca}^{2+}\right]_{\mathrm{i}}$ transients $(P<0.0001) .\left[\mathrm{Ca}^{2+}\right]_{\mathrm{i}}$ transients occurred with frequency similar to this measured in SN-MII oocytes (every $12.3 \pm 3.4 \mathrm{~min}, P>0.05$ ), but had lower amplitude (for the first $\left[\mathrm{Ca}^{2+}\right]_{\mathrm{i}}$ transient $0.42 \pm 0.17$, $P<0.001$ ) (Fig. 1D, E, F and G).

In conclusion, $\left[\mathrm{Ca}^{2+}\right]_{\mathrm{i}}$ oscillations at fertilization were severely impaired in MII oocytes derived from transcriptionally active GV oocytes (NSN-MII), suggesting that the mechanism of $\mathrm{Ca}^{2+}$ homeostasis in those oocytes is hindered.

\section{Oocytes of NSN origin contain less $\mathrm{Ca}^{2+}$ than $\mathrm{SN}$-derived oocytes}

To investigate whether the transcriptional status of an oocyte at the time of meiosis resumption affects its ability to accumulate $\mathrm{Ca}^{2+}$ ions, $\mathrm{SN}-\mathrm{MII}$ and $\mathrm{NSN}$ MIl oocytes were treated with either thapsigargin or A23187 ionophore. Thapsigargin is a SERCA inhibitor and allows to assess an amount of $\mathrm{Ca}^{2+}$ stored in ER, whereas A23187 ionophore stimulates pore formation and therefore can be used to estimate amount of $\mathrm{Ca}^{2+}$ in all cellular compartments.

In SN-MII oocytes $(n=68)$ thapsigargin triggered a multi-peaked $\left[\mathrm{Ca}^{2+}\right]_{i}$ transient that lasted for $9.5 \pm 2.6 \mathrm{~min}$ and rose up to $0.51 \pm 0.15$, while in NSN-MII oocytes $(n=15)$, the average $\left[\mathrm{Ca}^{2+}\right]_{i}$ transient was longer $(12.8 \pm 2.4 \mathrm{~min}, \quad P<0.0001)$ but lower $(0.31 \pm 0.13, P<0.0001)$ (Fig. $2 \mathrm{~A}, \mathrm{~B}$ and $\mathrm{C})$. In case of the ionophore treatment, SN-MII oocytes $(n=51)$ generated $\left[\mathrm{Ca}^{2+}\right]_{i}$ transient lasting for $4.9 \pm 0.9 \mathrm{~min}$ and reaching amplitude of $1.3 \pm 0.18$, while in NSNMII oocytes $(n=17)$, the $\left[\mathrm{Ca}^{2+}\right]_{\mathrm{i}}$ transient was shorter $(3.5 \pm 0.7 \mathrm{~min}, P<<0.0001)$ and had lower amplitude $(0.84 \pm 0.21, P<<0.0001)$ (Fig. $2 \mathrm{D}$ and E). Taken together, these results show that MII oocytes with the
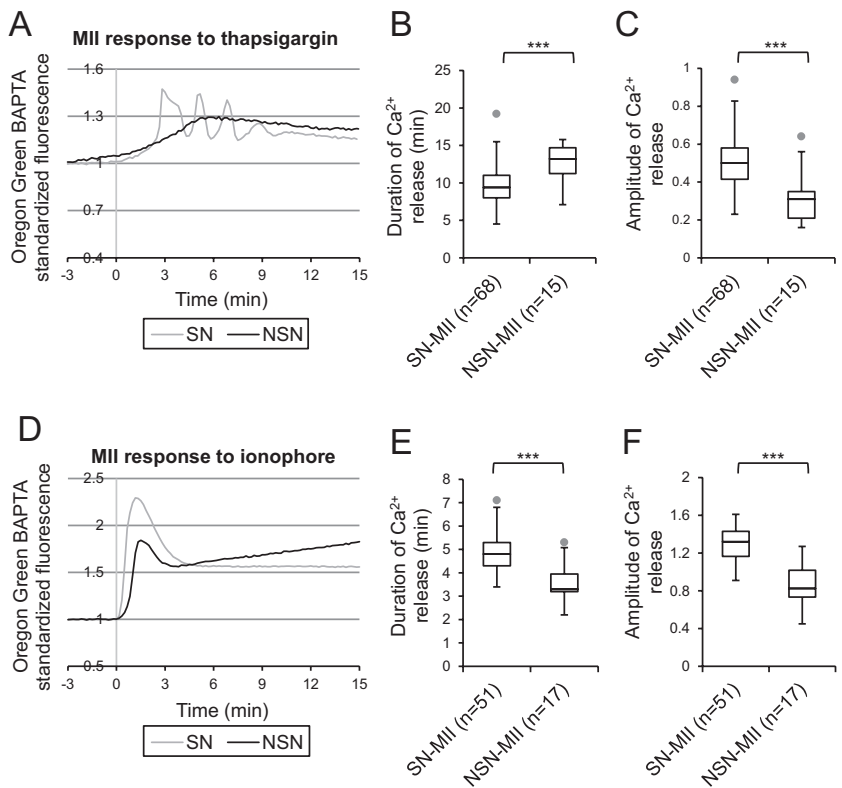

Figure 2 MII oocytes' response to thapsigargin and ionophore. (A) A representative $\mathrm{Ca}^{2+}$ response of $\mathrm{SN}$ - and $\mathrm{NSN}$-derived MII oocytes to thapsigargin. Duration (B) and amplitude $(\mathrm{C})$ of $\mathrm{Ca}^{2+}$ release in $\mathrm{SN}$ - and NSN-derived MII oocytes in response to thapsigargin. (D) A representative $\mathrm{Ca}^{2+}$ response of $\mathrm{SN}$ - and $\mathrm{NSN}$-derived MII oocytes to A23187 ionophore. Duration (E) and amplitude (F) of $\mathrm{Ca}^{2+}$ release in $\mathrm{SN}$ - and NSN-derived MII oocytes in response to ionophore. Graphs ( $\mathrm{B}$ and $\mathrm{C}, \mathrm{E}$ and $\mathrm{F}$ ) present median and the first and the third quartile values. The ends of the whisker are set at $1.5 \times \mathrm{IQR}$ above the third quartile and $1.5 \times \mathrm{IQR}$ below the first quartile. Dots show the minimum and maximum values if they are outside the range (outliers). ${ }^{* * *} P<0.001$. 
NSN origin (i.e. with unfinished transcription at the meiosis resumption) contain less $\mathrm{Ca}^{2+}$ ions than oocytes that completed transcription before the maturation onset (SN-MII oocytes).

As oocytes tend to accumulate $\mathrm{Ca}^{2+}$ during maturation (Tombes et al. 1992, Mehlmann \& Kline 1994, Jones et al. 1995), we next wished to examine whether the difference in $\mathrm{Ca}^{2+}$ content is due to a decreased ability of NSN oocytes to store $\mathrm{Ca}^{2+}$ during this period or whether it is present already in the GV stage. To this end, we analyzed $\mathrm{Ca}^{2+}$ content in GV stage oocytes. In both the thapsigargin and the ionophore treatments $\left[\mathrm{Ca}^{2+}\right]_{i}$ increase displayed by GV oocytes had similar amplitude as in MII oocytes, but lasted for shorter time, confirming that indeed oocytes accumulate $\mathrm{Ca}^{2+}$ ions during maturation. In SN-GV oocytes $(n=21)$ thapsigargin-induced $\left[\mathrm{Ca}^{2+}\right]_{i}$ transient with a mean amplitude of $0.55 \pm 0.14$ lasted for $3.77 \pm 1.17 \mathrm{~min}$. In NSN-GV oocytes $(n=32) \quad\left[\mathrm{Ca}^{2+}\right]_{\mathrm{i}}$ transient was shorter, lasting for $1.87 \pm 0.72 \mathrm{~min}$ and rose up only to $0.29 \pm 0.14$ (Fig. 3A, B and C; $P<<0.0001$ ). lonophoretreated SN-GV oocytes $(n=38)$ responded with a $\left[\mathrm{Ca}^{2+}\right]_{\mathrm{i}}$ transient with an average amplitude of $1.67 \pm 0.31$ and duration of $1.99 \pm 0.23 \mathrm{~min}$. NSN-GV $(n=38)$ oocytes generated a $\left[\mathrm{Ca}^{2+}\right]_{\mathrm{i}}$ transient of a lower amplitude
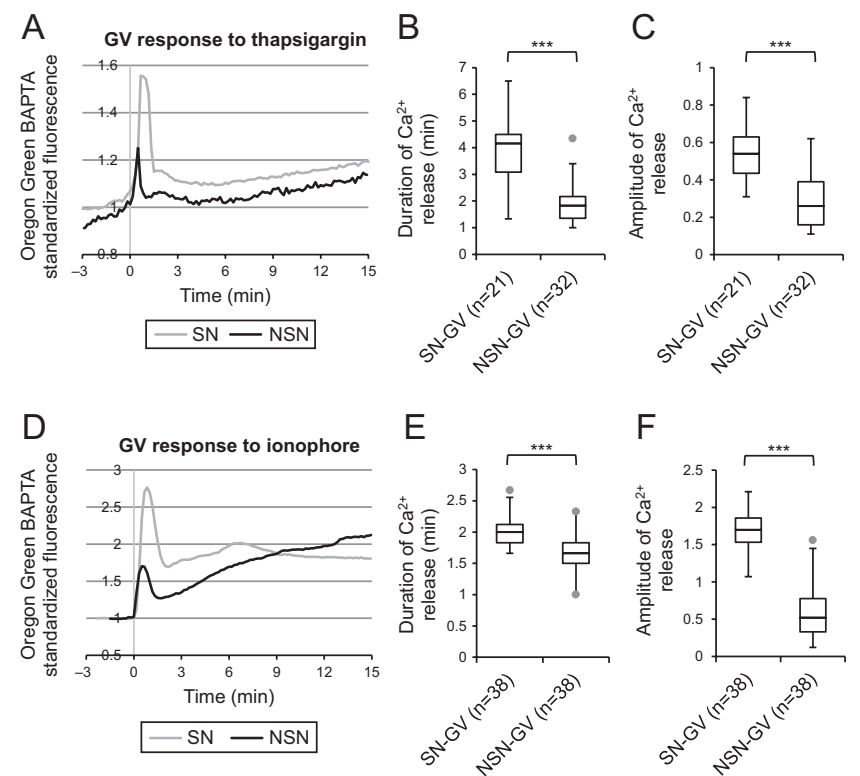

Figure 3 GV oocytes' response to thapsigargin and ionophore. (A) A representative $\mathrm{Ca}^{2+}$ response of $\mathrm{SN}$ and NSN GV oocytes to thapsigargin. Duration (B) and amplitude (C) of $\mathrm{Ca}^{2+}$ release in $\mathrm{SN}$ and NSN GV oocytes in response to thapsigargin. (D) A representative $\mathrm{Ca}^{2+}$ response of SN and NSN GV oocytes to $\mathrm{A} 23187$ ionophore (D). Duration (E) and amplitude (F) of $\mathrm{Ca}^{2+}$ release in $\mathrm{SN}$ and NSN GV oocytes in response to ionophore. Graphs (B and C, E and $\mathrm{F}$ ) present median and the first and the third quartile values. The ends of the whisker are set at $1.5 \times \mathrm{IQR}$ above the third quartile and $1.5 \times \mathrm{IQR}$ below the first quartile. Dots show the minimum and maximum values if they are outside the range (outliers). ${ }^{* * *} P<0.001$ of $0.62 \pm 0.37$ and lasting for only $1.64 \pm 0.3 \mathrm{~min}$ (Fig. 3D and $\mathrm{E} ; P<<0.0001$ ). These results indicate, that the difference in $\mathrm{Ca}^{2+}$ content between $\mathrm{SN}$ - and NSN-derived oocytes is already visible at GV stage, however, due to constraints of our analysis we cannot unequivocally determine whether it is additionally enhanced by a defective $\mathrm{Ca}^{2+}$ accumulation during in vitro maturation.

\section{Expression of IP3R1 is lower in NSN-derived oocytes}

To investigate whether the differences in $\mathrm{Ca}^{2+}$ homeostasis between oocytes with the NSN and SN origin are related to altered expression of genes involved in this process, we analyzed mRNA and protein levels of two main regulators of $\left[\mathrm{Ca}^{2+}\right]_{i}$ oscillations - IP3R1 and SERCA2. The real-time RT-PCR showed that there are no significant differences in the amount of mRNA for these two proteins between SN and NSN oocytes either in GV or in MII stage (Fig. 4A and B). However, when we examined the protein level of IP3R1 (in case of SERCA2 we were not able to detect it on a Western blot), we noticed that it is significantly less abundant in NSN-GV than in SN-GV oocytes. The difference was maintained after $16 \mathrm{~h}$, when oocytes achieved $\mathrm{MI}$ or MIl stage (Fig. 4C). In summary, although NSN-derived oocytes contain the same amount of mRNA for IP3R1 and SERCA as SN oocytes, the IP3R1 expression is decreased on the protein level, suggesting that either the protein synthesis is less effective or the protein itself is less stable.
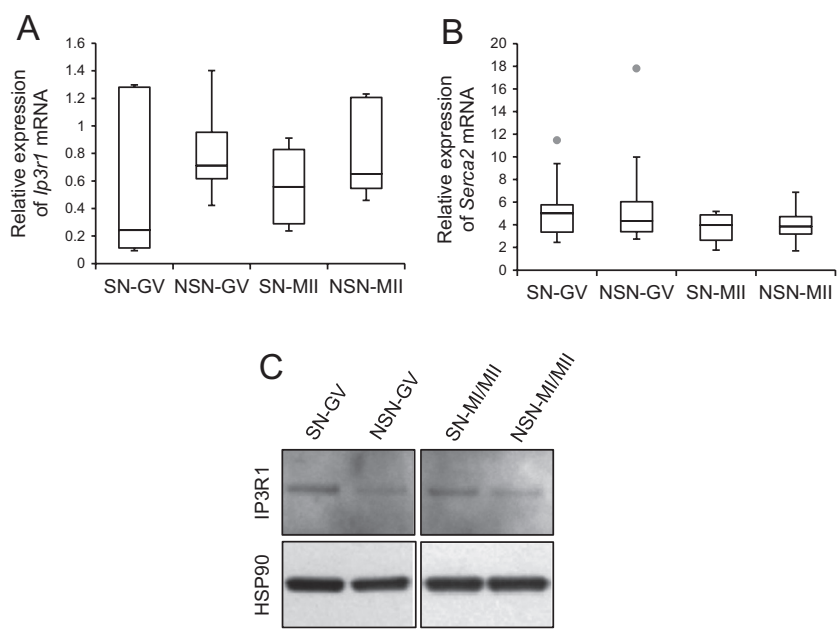

Figure 4 Expression of IP3R1 and SERCA2. Relative expression of Ip3r1 (A) and Serca2 (B) mRNA in SN- and NSN-derived oocytes. Graphs present median and the first and the third quartile values. The ends of the whisker are set at $1.5 \times \mathrm{IQR}$ above the third quartile and $1.5 \times$ IQR below the first quartile. Dots show the minimum and maximum values if they are outside the range (outliers). (C) Westernblot of IP3R1 protein expressed in SN- and NSN GV oocytes and SN and NSN-derived oocytes that achieved MI or MII stage (MI/MII). HSP90 was used as a reference housekeeping protein. 


\section{SN and NSN oocytes differ in $\mathrm{Ca}^{2+}$ homeostasis regulation at maturation}

$\left[\mathrm{Ca}^{2+}\right]_{\mathrm{i}}$ oscillations can also take place during GV stage and meiotic maturation (Carroll \& Swann 1992, Carroll et al. 1994, Wakai \& Fissore 2019), therefore, we decided to look into this process. We observed it in $72.4 \%(55 / 76)$ of transcriptionally inactive oocytes (SN) and $63.8 \%(30 / 47)$ of transcriptionally active oocytes (NSN) that resumed meiosis and in all (2/2) SN and $79.2 \%(19 / 24)$ NSN oocytes that remain arrested in the GV stage. We distinguished three pronounced patterns of $\mathrm{Ca}^{2+}$ release during maturation. Type 1 was characterized by at least $15\left[\mathrm{Ca}^{2+}\right]_{i}$ transients of variable amplitude lasting for at least $100 \mathrm{~min}$, type 2 had less than $15\left[\mathrm{Ca}^{2+}\right]_{\mathrm{i}}$ transients over less than $100 \mathrm{~min}$, while in type 3 we did not observe any $\mathrm{Ca}^{2+}$ release (Fig. 5A, B and $\mathrm{C}$ ). Although frequency of the type 2 and 3 responses in $\mathrm{SN}$ - and NSN-derived maturing oocytes was similar (64.5\% (49/76) and $27.6 \%(21 / 76)$ vs $63.8 \%(30 / 47)$ and $36.2 \%(17 / 47)$ respectively), the type 1 pattern occurred only in SN-derived maturing oocytes $(7.9 \%,(6 / 76))$. On the other hand, all SN oocytes that remained arrested in the GV stage displayed the type 1 pattern, whereas

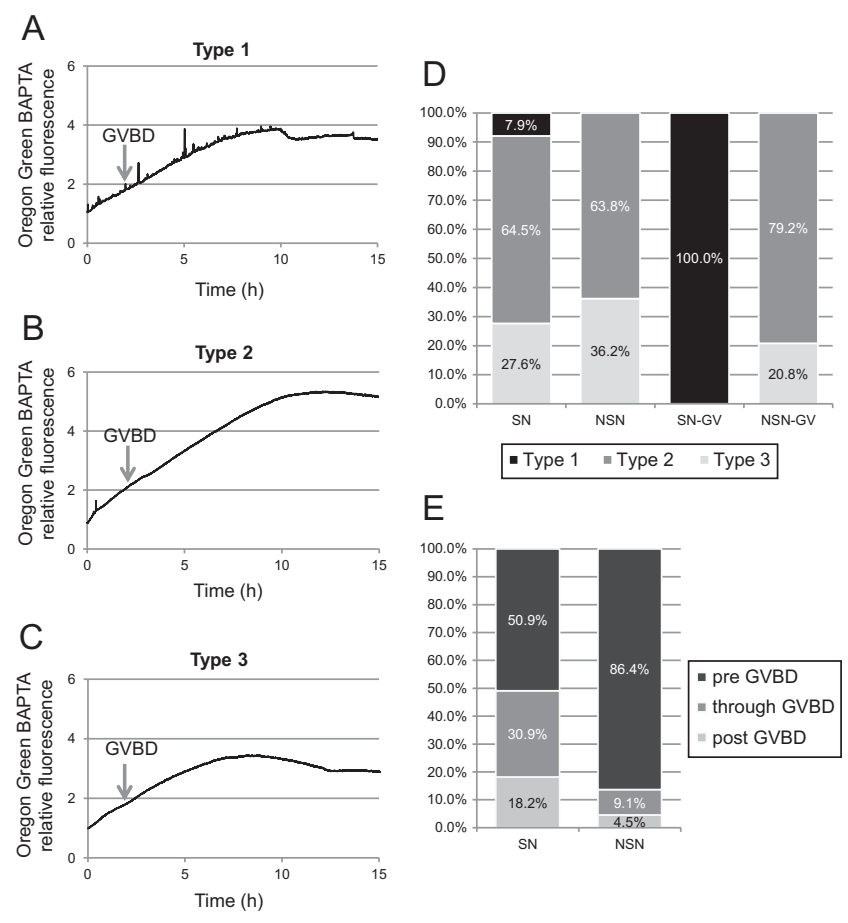

Figure 5 Spontaneous $\left[\mathrm{Ca}^{2+}\right]_{i}$ oscillations during maturation of $\mathrm{SN}$ and NSN oocytes. (A, B and C) Three types of $\mathrm{Ca}^{2+}$ release observed in maturing oocytes. The arrowheads indicate the moment of GVBD. A detailed description of the types in the main text. (D) Frequency of the $\mathrm{Ca}^{2+}$ release patterns in SN and NSN oocytes. (E) Time of initiation and termination of $\left[\mathrm{Ca}^{2+}\right]_{i}$ oscillations in relation to GVBD: 'pre GVBD' $-\left[\mathrm{Ca}^{2+}\right]_{\mathrm{i}}$ transients started and ended before GVBD; 'through $\mathrm{GVBD}^{\prime}-\left[\mathrm{Ca}^{2+}\right]_{i}$ oscillations were initiated before GVBD, but ceased after GVBD; 'post GVBD' $-\left[\mathrm{Ca}^{2+}\right]_{i}$ transients started and ended after GVBD. none of the NSN-GV oocytes did so. 79.2\% (19/24) of NSN oocytes arrested at the GV stage exhibited type 2 pattern, and 20.8\% (5/24) - type 3 (Fig. 5D).

In case of oocytes that resumed meiosis, we also examined when, in relation to the GVBD, $\left[\mathrm{Ca}^{2+}\right]_{\mathrm{i}}$ oscillations were initiated and when they ceased. In the vast majority $\left(86.4 \%(19 / 22)\right.$ of $\mathrm{NSN}$ oocytes $\left[\mathrm{Ca}^{2+}\right]_{\mathrm{i}}$ oscillations were initiated and ceased before GVBD ('pre GVBD'). SN oocytes were a more diversified group with only $50.9 \%(28 / 55)$ of oocytes having 'pre GVBD' $\left[\mathrm{Ca}^{2+}\right]_{\mathrm{i}}$ oscillations. $30.9 \%$ (17/55) of SN oocytes displayed $\left[\mathrm{Ca}^{2+}\right]_{i}$ oscillations starting before and lasting through GVBD ('through GVBD'; vs only $9.1 \%$ in NSN) and $18.2 \%(10 / 55)-\left[\mathrm{Ca}^{2+}\right]_{\mathrm{i}}$ oscillations initiated after GVBD ('post GVBD'; vs only 4.5\% in NSN) $(P<0.05)$ (Fig. 5E).

$\left[\mathrm{Ca}^{2+}\right]_{i}$ oscillations in NSN-derived maturing oocytes lasted on average only for $30.6 \pm 29.3 \mathrm{~min}$ with $2.33 \pm 1.56 \mathrm{Ca}^{2+}$ transients, while $\mathrm{SN}$-derived maturing oocytes oscillated for $3.24 \pm 4.37 \mathrm{~h}(P<0.05)$ with $10.71 \pm 16.44 \mathrm{Ca}^{2+}$ transients $(P<0.05)$. Average transient amplitude equaled $0.21 \pm 0.14$ for maturing oocytes of the SN origin and $0.12 \pm 0.08(P<0.001)$ for those of the NSN origin (Fig. 6A, B and C).

Interestingly, oocytes of both $\mathrm{SN}$ - and NSN-origins that were not able to resume meiosis and remained in the GV stage, showed longer $\left[\mathrm{Ca}^{2+}\right]_{i}$ oscillations with more numerous $\left[\mathrm{Ca}^{2+}\right]_{i}$ transients than their maturing counterparts. SN GV-arrested oocytes $(n=2)$ had $\left[\mathrm{Ca}^{2+}\right]_{\mathrm{i}}$ oscillations lasting for $3.8 \pm 0.12 \mathrm{~h}$ with over 230, dynamically repeating $\left[\mathrm{Ca}^{2+}\right]_{i}$ transients of $0.33 \pm 0.04$ amplitude. NSN GV-arrested oocytes (19/24) oscillated for $3.01 \pm 3.9 \mathrm{~h}(P<0.05$ in comparison to oocytes that resumed meiosis) with $4.47 \pm 3.94\left[\mathrm{Ca}^{2+}\right]_{\mathrm{i}}$ transients $(P>0.05)$ of $0.15 \pm 0.17$ amplitude $(P<0.05)$ (Fig. 6D, $\mathrm{E}$ and $\mathrm{F})$.

To conclude, $\left[\mathrm{Ca}^{2+}\right]_{i}$ oscillations in NSN-derived oocytes are usually less numerous and shorter than in $\mathrm{SN}$-derived oocytes. However, GV-arrested oocytes of both these origins tend to generate more intensive $\left[\mathrm{Ca}^{2+}\right]_{\mathrm{i}}$ oscillations than those that resumed meiosis.

\section{Discussion}

In this paper we investigated whether transcriptional status of mouse oocytes at the onset of meiotic maturation affects $\mathrm{Ca}^{2+}$ homeostasis in these cells. Taking into account the pertinence of $\mathrm{Ca}^{2+}$ signaling in oocytes, especially fertilization-induced $\left[\mathrm{Ca}^{2+}\right]_{\mathrm{i}}$ oscillations that trigger meiosis completion and initiate and regulate the embryonic development (Ozil et al. 2005, 2006, Campbell \& Swann 2006, Madgwick et al. 2006, Shoji et al. 2006, Tóth et al. 2006, Burkart et al. 2012; reviewed in Ducibella et al. 2006), we hypothesized that if $\left[\mathrm{Ca}^{2+}\right]_{\mathrm{i}}$ oscillations were disrupted in NSN-derived oocytes, it could explain, at least partially, their low developmental capabilities (Zuccotti et al. 2002, Inoue et al. 2008; reviewed in Tan et al. 2009). 

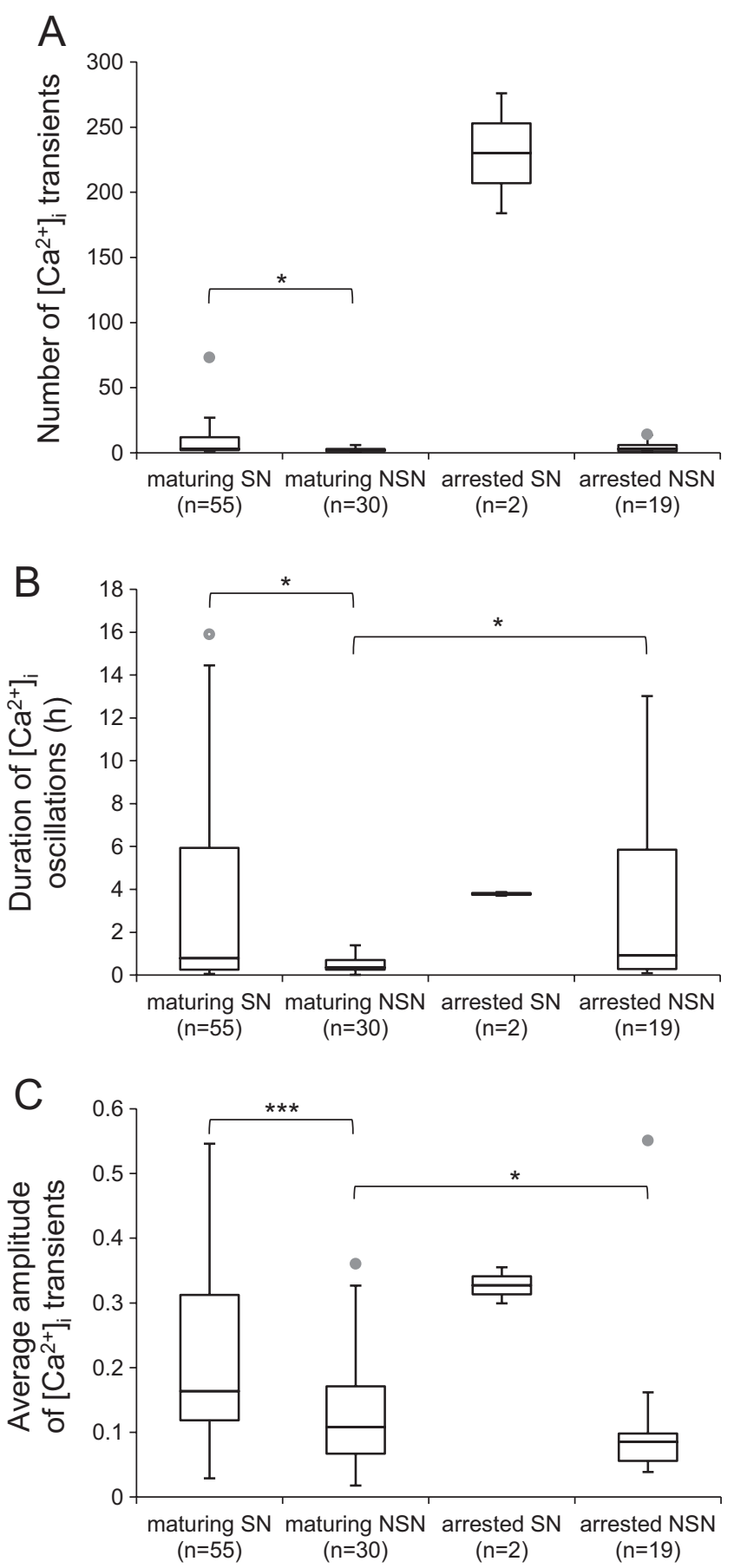

Figure 6 Quantitative analysis of the spontaneous $\mathrm{Ca}^{2+}$ release in maturing $\mathrm{SN}$ and $\mathrm{NSN}$ oocytes. (A) Number of $\left[\mathrm{Ca}^{2+}\right]_{\mathrm{i}}$ transients, (B) duration of $\left[\mathrm{Ca}^{2+}\right]_{\mathrm{i}}$ oscillations, (C) amplitude of the first $\left[\mathrm{Ca}^{2+}\right]_{i}$ transient registered for the spontaneous $\mathrm{Ca}^{2+}$ release in maturing $\mathrm{SN}$ and NSN oocytes. Graphs (A, B and C) present median and the first and the third quartile values. The ends of the whisker are set at $1.5 \times \mathrm{IQR}$ above the third quartile and $1.5 \times \mathrm{IQR}$ below the first quartile. Dots show the minimum and maximum values if they are outside the range (outliers). ${ }^{*} P<0.05$, $* * * P<0.001$.
Indeed, we revealed that MII oocytes derived from transcriptionally active NSN-GV oocytes exhibit an abnormal pattern of sperm-triggered $\left[\mathrm{Ca}^{2+}\right]_{i}$ oscillations compared to oocytes derived from transcriptionally inactive $\mathrm{SN}-\mathrm{GV}$ oocytes. $\left[\mathrm{Ca}^{2+}\right]_{i}$ oscillations in NSNderived oocytes display fewer $\left[\mathrm{Ca}^{2+}\right]_{i}$ transients of a lower amplitude and those $\left[\mathrm{Ca}^{2+}\right]_{i}$ oscillations last for shorter time than in $\mathrm{SN}$-derived oocytes. This result accords with our other observation that NSN-derived oocytes contain less $\mathrm{Ca}^{2+}$ and express less IP3R1 protein. It has been shown that decreased amount of $\mathrm{Ca}^{2+}$ stored in oocytes leads to aberrant pattern of $\left[\mathrm{Ca}^{2+}\right]_{i}$ oscillations at fertilization: the whole event is shorter, $\left[\mathrm{Ca}^{2+}\right]_{\mathrm{i}}$ transients are less frequent and have lower amplitudes (Miao et al. 2012, Wakai et al. 2013). $\mathrm{Ca}^{2+}$ stores are similarly depleted in postovulatory aged oocytes (Takahashi et al. 2000, Lord \& Aitken 2013), and $\left[\mathrm{Ca}^{2+}\right]_{i}$ oscillations at fertilization in these oocytes are also anomalous, with the $\left[\mathrm{Ca}^{2+}\right]_{i}$ transients being lower in amplitude but more frequent than in fresh oocytes (Igarashi et al. 1997, Takahashi et al. 2003). Importantly, we have also shown that difference in the $\mathrm{Ca}^{2+}$ content between $\mathrm{SN}$ - and $\mathrm{NSN}$-derived oocytes is already visible at the GV stage. This could be due to the fact that in ovaries transport of ions and low molecular weight molecules, such as secondary messengers, amino acids and nucleotides, through the gap junctions between the cumulus cells and NSN oocytes may be still active, as it has been shown for bovine oocytes (Lodde et al. 2007). It is then possible, that NSN oocytes do not accumulate enough of these factors before their maturation in vitro is induced, which, in turn, negatively impacts their ability to maintain ionic homeostasis (Kumar \& Gilula 1996), transcription (De La Fuente \& Eppig 2001), or translation and protein phosphorylation (Colonna \& Mangia 1983, Colonna et al. 1989, Haghighat \& Van Winkle 1990).

Similarly, it has been indicated that correct pattern of $\left[\mathrm{Ca}^{2+}\right]_{i}$ oscillations in fertilized oocytes depends on the amount of IP3R1 expressed (Parrington et al. 1998, Jellerette et al. 2000, 2004, Jędrusik et al. 2007, Lee et al. 2010). Interestingly, we showed that IP3R1 protein content is reduced in NSN as compared to SN oocytes, whereas mRNA for this protein is expressed at a similar level in both examined groups. This suggests that IP3R1 protein expression is deregulated translationally or post-translationally. Recent studies have suggested that ability of NSN oocytes to store mRNA may be reduced due to a lower number of cytoplasmic lattices (CPL), fibrillar matrices composed of protein and RNA, which seem to contain most of oocyte's ribosomes (Monti et al. 2013). CPL shortage may also deregulate translation (Yurttas et al. 2008). We cannot also exclude that IP3R1 undergoes a faster degradation in NSN oocytes due to for example amino acid deprivation (Dever 2002) that may be caused by potential premature closure of the 
junctional transport between oocytes and cumulus cells (see the previous paragraph; Lodde et al. 2007).

It is also possible that in MII oocytes of NSN origin, metabolism of phosphatidylinositol (PI) is disturbed, which results in deficiency of indigenous $\mathbb{I P}_{3}$. This hypothesis is in line with the literature reporting that in NSN oocytes expression of enzymes producing $\mathrm{Pl}, \mathrm{PI}(4) \mathrm{P}$ (phosphatidylinositol 4-phosphate) and $\mathrm{PI}(4,5) \mathrm{P} 2$ (phosphatidylinositol (4,5)-bisphosphate) is reduced (Ma et al. 2013). It is also possible that IP3R1 receptors in NSN-derived MII oocytes have lower affinity to $\mathrm{IP}_{3}$. Previous studies have shown that the sensitivity of IP3R1 to $I_{3}$ increases during oocyte maturation due to phosphorylation (Lee et al. 2006, Sun et al. 2009, Wakai et al. 2012, Zhang et al. 2015) and it is possible that this event is impaired in NSN oocytes. It has been shown that expression of MAP kinase, the main enzyme responsible for IP3R1 phosphorylation (Lee et al. 2006), is downregulated in mouse NSN oocytes (Ma et al. 2013).

Finally, we showed that NSN oocytes display altered $\mathrm{Ca}^{2+}$ signaling already during meiotic maturation. $\left[\mathrm{Ca}^{2+}\right]_{\mathrm{i}}$ oscillations in NSN oocytes are shorter and with fewer $\left[\mathrm{Ca}^{2+}\right]_{\mathrm{i}}$ transients. This corresponds with observations of Carroll et al. (1994) who reported that ability to generate $\left[\mathrm{Ca}^{2+}\right]_{i}$ oscillations during maturation reflects developmental capabilities of oocytes: small, meiotically incompetent oocytes were less likely to generate $\left[\mathrm{Ca}^{2+}\right]_{\mathrm{i}}$ oscillations compared to competent oocytes. However, Carroll et al. (1994) showed also that oocytes arrested in GV stage did not exhibit $\left[\mathrm{Ca}^{2+}\right]_{i}$ oscillations at all, whereas in our conditions such oocytes manifested more $\left[\mathrm{Ca}^{2+}\right]_{i}$ transients and overall longer $\left[\mathrm{Ca}^{2+}\right]_{i}$ oscillations than those that resumed meiosis. It is likely that impairment of $\left[\mathrm{Ca}^{2+}\right]_{i}$ oscillations recorded in NSNderived maturing oocytes, as compared to $\mathrm{SN}$-derived ones, is caused by the same factors that negatively affect fertilization-induced $\left[\mathrm{Ca}^{2+}\right]_{\mathrm{i}}$ oscillations in NSN-MII oocytes, that is by the lower amounts of IP3R1 and $\mathrm{Ca}^{2+}$ ions stored in the cell. It is also possible that hindered PI metabolism and decreased functionality of IP3R1 are involved.

Although it has been suggested that $\mathrm{Ca}^{2+}$ participates in the signaling pathway linking a decrease in CAMP concentration in oocytes and their meiotic resumption (De Felici et al. 1991; reviewed in Tosti 2006), GVBD is $\mathrm{Ca}^{2+}$ independent (Carroll \& Swann 1992, Tombes et al. 1992). Therefore, the lower rate of meiotic resumption in NSN oocytes probably is not caused by the hindered $\mathrm{Ca}^{2+}$ release during meiotic maturation. However, the altered pattern of $\left[\mathrm{Ca}^{2+}\right]_{\mathrm{i}}$ oscillations at maturation may influence the processes of cytoplasmic maturation. Recently, it has been reported that $\left[\mathrm{Ca}^{2+}\right]_{\mathrm{i}}$ oscillations in immature oocytes stimulate their mitochondrial metabolism (Wakai \& Fissore 2019). Moreover, it has been shown that $\mathrm{Ca}^{2+}$ signaling has a role in cell membrane trafficking in somatic cells (reviewed in Li et al. 2013, van der Kant \& Neefjes 2014) and a local rise in $\left[\mathrm{Ca}^{2+}\right]_{i}$ may trigger closure of gap-junction channels (Rose \& Loewenstein 1975). It is therefore possible that impaired $\mathrm{Ca}^{2+}$ homeostasis in oocytes affects their cellular trafficking and junctional communication with cumulus cells.

In summary, our results indicate NSN-derived oocytes display altered $\mathrm{Ca}^{2+}$ signaling, when compared to $\mathrm{SN}$-derived counterparts. It may be, at least partially, caused by the unfinished transcription in NSN oocytes; however, it is likely that other properties of NSN oocytes, for example, potentially incomplete trans-junctional import from the surrounding cumulus cells, also play a role here. We postulate that defective $\mathrm{Ca}^{2+}$ homeostasis is one of the reasons for the low developmental capabilities of NSN oocytes. Importantly, better understanding of phenotypical differences between SN and NSN oocytes, as well as their molecular background, is crucial to optimize procedures of in vitro oocyte maturation. As this approach has been applied in assisted reproduction of farm animals and more and more intensely explored in infertility clinics (reviewed in Sauerbrun-Cutler et al. 2015), we definitely need to examine its mechanisms more closely.

\section{Declaration of interest}

The authors declare that there is no conflict of interest that could be perceived as prejudicing the impartiality of the research reported.

\section{Funding}

The study was funded by the SONATA grant (UMO-2012/07/D/ NZ5/04301) from the National Science Centre (Poland) to A A.

\section{Author contribution statement}

M F conducted the experiments, analyzed the data and drafted the manuscript. K S consulted the PCR experiments. $\mathrm{T}$ I conducted some of the Western blot experiments. A A planned the experiments, conducted some of them and revised the manuscript.

\section{Acknowledgements}

The authors would like to thank Prof Karl Swann for a valuable scientific discussion, Dr Robert Milewski for his help in statistical analysis, Dariusz Maluchnik and Aleksander Chlebowski for their assistance in imaging, and colleagues from the Department of Cytology, University of Warsaw for providing us with some of the primary and secondary antibodies.

\section{References}

Ajduk A, Małagocki A \& Maleszewski M 2008 Cytoplasmic maturation of mammalian oocytes: development of a mechanism responsible for sperm-induced Ca2+ oscillations. Reproductive Biology 8 3-22. (https:// doi.org/10.1016/S1642-431X(12)60001-1) 
Berridge MJ, Bootman MD \& Roderick HL 2003 Calcium signalling: dynamics, homeostasis and remodelling. Nature Reviews. Molecular Cell Biology 4 517-529. (https://doi.org/10.1038/nrm1155)

Bouniol-Baly C, Hamraoui L, Guibert J, Beaujean N, Szöllösi MS \& Debey P 1999 Differential transcriptional activity associated with chromatin configuration in fully grown mouse germinal vesicle oocytes. Biology of Reproduction 60 580-587. (https://doi.org/10.1095/biolreprod60.3.580)

Burkart AD, Xiong B, Baibakov B, Jiménez-Movilla M \& Dean J 2012 Ovastacin, a cortical granule protease, cleaves ZP2 in the zona pellucida to prevent polyspermy. Journal of Cell Biology 197 37-44. (https://doi. org/10.1083/jcb.201112094)

Campbell K \& Swann K 2006 Ca2+ oscillations stimulate an ATP increase during fertilization of mouse eggs. Developmental Biology 298 225-233. (https://doi.org/10.1016/j.ydbio.2006.06.032)

Carroll J \& Swann K 1992 Spontaneous cytosolic calcium oscillations driven by inositol trisphosphate occur during in vitro maturation of mouse oocytes. Journal of Biological Chemistry $26711196-11201$.

Carroll J, Swann K, Whittingham D \& Whitaker M 1994 Spatiotemporal dynamics of intracellular [Ca2+]i oscillations during the growth and meiotic maturation of mouse oocytes. Development 120 3507-3517.

Colonna R \& Mangia F 1983 Mechanisms of amino acid uptake in cumulusenclosed mouse oocytes. Biology of Reproduction 28 797-803. (https:// doi.org/10.1095/biolreprod28.4.797)

Colonna R, Cecconi S, Tatone C, Mangia F \& Buccione R 1989 Somatic cell-oocyte interactions in mouse oogenesis: stage-specific regulation of mouse oocyte protein phosphorylation by granulosa cells. Developmental Biology 133 305-308. (https://doi.org/10.1016/00121606(89)90321-7)

Corbett EF, Oikawa K, Francois P, Tessier DC, Kay C, Bergeron JJ, Thomas DY, Krause KH \& Michalak M 1999 Ca2+regulation of interactions between endoplasmic reticulum chaperones. Journal of Biological Chemistry 274 6203-6211. (https://doi.org/10.1074/jbc.274.10.6203)

Debey P, Szöllösi MS, Szöllösi D, Vautier D, Girousse A \& Besombes D 1993 Competent mouse oocytes isolated from antral follicles exhibit different chromatin organization and follow different maturation dynamics. Molecular Reproduction and Development 36 59-74. (https:// doi.org/10.1002/mrd.1080360110)

De Felici M, Dolci S \& Siracusa G 1991 An increase of intracellular free $\mathrm{Ca} 2+$ is essential for spontaneous meiotic resumption by mouse oocytes. Journal of Experimental Zoology 260 401-405. (https://doi.org/10.1002/ jez.1402600314)

De La Fuente R \& Eppig J 2001 Transcriptional activity of the mouse oocyte genome: companion granulosa cells modulate transcription and chromatin remodeling. Developmental Biology 229 224-236. (https:// doi.org/10.1006/dbio.2000.9947)

Dever TE 2002 Gene-specific regulation by general translation factors. Cell 108 545-556. (https://doi.org/10.1016/S0092-8674(02)00642-6)

Ducibella T, Schultz RM \& Ozil JP 2006 Role of calcium signals in early development. Seminars in Cell and Developmental Biology 17 324-332. (https://doi.org/10.1016/j.semcdb.2006.02.010)

Dumollard R, Marangos P, Fitzharris G, Swann K, Duchen M \& Carroll J 2004 Sperm-triggered [Ca2+] oscillations and $\mathrm{Ca} 2+$ homeostasis in the mouse egg have an absolute requirement for mitochondrial ATP production. Development 131 3057-3067. (https://doi.org/10.1242/ dev.01181)

Fraser LR 1982 p-Aminobenzamidine, an acrosin inhibitor, inhibits mouse sperm penetration of the zona pellucida but not the acrosome reaction. Journal of Reproduction and Fertility 65 185-194. (https://doi. org/10.1530/jrf.0.0650185)

Fulton BP \& Whittingham DG 1978 Activation of mammalian oocytes by intracellular injection of calcium. Nature 273 149-151. (https://doi. org/10.1038/273149a0)

Gilchrist RB, Lane M \& Thompson JG 2008 Oocyte-secreted factors: regulators of cumulus cell function and oocyte quality. Human Reproduction Update 14 159-177. (https://doi.org/10.1093/humupd/ dmm040)

Haghighat N \& Van Winkle LJ 1990 Developmental change in follicular cell-enhanced amino acid uptake into mouse oocytes that depends on intact gap junctions and transport system gly. Journal of Experimental Zoology 253 71-82. (https://doi.org/10.1002/jez.1402530110)

Igarashi H, Takahashi E, Hiroi M \& Doi K 1997 Aging-related changes in calcium oscillations in fertilized mouse oocytes. Molecular Reproduction and Development 48 383-390. (https://doi.org/10.1002/(SICI)10982795(199711)48:3<383::AID-MRD12>3.0.CO;2-X)

Inoue A, Nakajima R, Nagata M \& Aoki F 2008 Contribution of the oocyte nucleus and cytoplasm to the determination of meiotic and developmental competence in mice. Human Reproduction 23 1377-1384. (https://doi.org/10.1093/humrep/den096)

Jędrusik A, Ajduk A, Pomorski P \& Maleszewski M 2007 Mouse oocytes fertilised by ICSI during in vitro maturation retain the ability to be activated after refertilisation in metaphase II and can generate Ca2+ oscillations. BMC Developmental Biology 7 72. (https://doi. org/10.1186/1471-213X-7-72)

Jellerette T, He CL, Wu H, Parys JB \& Fissore RA 2000 Down-regulation of the inositol 1,4,5-trisphosphate receptor in mouse eggs following fertilization or parthenogenetic activation. Developmental Biology 223 238-250. (https://doi.org/10.1006/dbio.2000.9675)

Jellerette T, Kurokawa M, Lee B, Malcuit C, Yoon SY, Smyth J, Vermassen E, De Smedt H, Parys JB \& Fissore RA 2004 Cell cycle-coupled $[\mathrm{Ca} 2+] \mathrm{i}$ oscillations in mouse zygotes and function of the inositol 1,4,5-trisphosphate receptor-1. Developmental Biology 274 94-109. (doi:10.1016/j.ydbio.2004.06.020)

Jones KT, Carroll J \& Whittingham DG 1995 Ionomycin, thapsigargin, ryanodine, and sperm induced $\mathrm{Ca} 2+$ release increase during meiotic maturation of mouse oocytes. Journal of Biological Chemistry 270 6671-6677. (https://doi.org/10.1074/jbc.270.12.6671)

Kageyama S, Liu H, Kaneko N, Ooga M, Nagata M \& Aoki F 2007 Alterations in epigenetic modifications during oocyte growth in mice. Reproduction 133 85-94. (https://doi.org/10.1530/REP-06-0025)

Kumar NM \& Gilula NB 1996 The Gap junction communication | channel. Cell 84 381-388. (https://doi.org/10.1016/S00928674(00)81282-9)

Larman MG, Saunders CM, Carroll J, Lai FA \& Swann K 2004 Cell cycledependent $\mathrm{Ca} 2+$ oscillations in mouse embryos are regulated by nuclear targeting of PLCzeta. Journal of Cell Science 117 2513-2521. (https:// doi.org/10.1242/jcs.01109)

Lee B, Vermassen E, Yoon S-Y, Vanderheyden V, Ito J, Alfandari D, De Smedt H, Parys JB \& Fissore RA 2006 Phosphorylation of IP3R1 and the regulation of $[\mathrm{Ca} 2+]$ i responses at fertilization: a role for the MAP kinase pathway. Development 133 4355-4365. (https://doi.org/10.1242/ dev.02624)

Lee B, Yoon SY, Malcuit C, Parys JB \& Fissore RA 2010 Inositol 1,4,5-trisphosphate receptor 1 degradation in mouse eggs and impact on [Ca2+]i oscillations. Journal of Cellular Physiology 222 238-247. (https:// doi.org/10.1002/jcp.21945)

Li Y \& Camacho P 2004 Ca2+-dependent redox modulation of SERCA 2b by ERp57. Journal of Cell Biology 164 35-46. (https://doi.org/10.1083/ jcb.200307010)

Li X, Garrity AG \& Xu H 2013 Regulation of membrane trafficking by signalling on endosomal and lysosomal membranes. Journal of Physiology 591 4389-4401. (https://doi.org/10.1113/jphysiol.2013.258301)

Liu H \& Aoki F 2002 Transcriptional activity associated with meiotic competence in fully grown mouse GV oocytes. Zygote 10 327-332. (https://doi.org/10.1017/S0967199402004069)

Livak KJ \& Schmittgen TD 2001 Analysis of relative gene expression data using real-time quantitative PCR and the 2(-Delta Delta C(T)) Method. Methods 25 402-408. (https://doi.org/10.1006/meth.2001.1262)

Lodde V, Modina S, Galbusera C, Franciosi F \& Luciano AM 2007 Largescale chromatin remodeling in germinal vesicle bovine oocytes: interplay with gap junction functionality and developmental competence. Molecular Reproduction and Development 74 740-749. (https://doi. org/10.1002/mrd.20639)

Lord T \& Aitken RJ 2013 Oxidative stress and ageing of the post-ovulatory oocyte. Reproduction 146 R217-R227. (https://doi.org/10.1530/REP13-0111)

Ma JY, Li M, Luo YB, Song S, Tian D, Yang J, Zhang B, Hou Y, Schatten H, Liu Z et al. 2013 Maternal factors required for oocyte developmental competence in mice: transcriptome analysis of non-surrounded nucleolus (NSN) and surrounded nucleolus (SN) oocytes. Cell Cycle 12 1928-1938. (https://doi.org/10.4161/cc.24991)

Madgwick S, Hansen DV, Levasseur M, Jackson PK \& Jones KT 2006 Mouse Emi2 is required to enter meiosis II by reestablishing cyclin B1 during interkinesis. Journal of Cell Biology 174 791-801. (https://doi. org/10.1083/jcb.200604140) 
Marangos P, Fitzharris G \& Carroll J 2003 Ca2+ oscillations at fertilization in mammals are regulated by the formation of pronuclei. Development 130 1461-1472. (https://doi.org/10.1242/dev.00340)

Masui Y 1985 Meiotic arrest in animal oocytes. In Biology of Fertilization V1: Model Systems and Oogenesis vol. 1, pp 189-221. Eds C Metz \& A Monroy. Orlando: Academic Press.

Mattson BA \& Albertini DF 1990 Oogenesis: chromatin and microtubule dynamics during meiotic prophase. Molecular Reproduction and Development 25 374-383. (https://doi.org/10.1002/mrd.1080250411)

Mehlmann LM \& Kline D 1994 Regulation of intracellular calcium in the mouse egg: calcium release in response to sperm or inositol trisphosphate is enhanced after meiotic maturation. Biology of Reproduction 51 1088-1098. (https://doi.org/10.1095/biolreprod51.6.1088)

Miao YL, Stein P, Jefferson WN, Padilla-Banks E \& Williams CJ 2012 Calcium influx-mediated signaling is required for complete mouse egg activation. PNAS $\mathbf{1 0 9}$ 4169-4174. (https://doi.org/10.1073/ pnas.1112333109)

Monti M, Zanoni M, Calligaro A, Ko MS, Mauri P \& Redi CA 2013 Developmental arrest and mouse antral not-surrounded nucleolus oocytes. Biology of Reproduction 88 2. (https://doi.org/10.1095/ biolreprod.112.103887)

Ozil JP, Markoulaki S, Tóth S, Matson S, Banrezes B, Knott JG, Schultz RM, Huneau D \& Ducibella T 2005 Egg activation events are regulated by the duration of a sustained [Ca2+]cyt signal in the mouse. Developmental Biology 282 39-54. (https://doi.org/10.1016/j.ydbio.2005.02.035)

Ozil JP, Banrezes B, Tóth S, Pan H \& Schultz RM 2006 Ca2+ oscillatory pattern in fertilized mouse eggs affects gene expression and development to term. Developmental Biology 300 534-544. (https://doi.org/10.1016/j. ydbio.2006.08.041)

Parrington J, Swann K, Shevchenko VI, Sesay AK \& Lai FA 1996 Calcium oscillations in mammalian eggs triggered by a soluble sperm protein. Nature 379 364-368. (https://doi.org/10.1038/379364a0)

Parrington J, Brind S, De Smedt H, Gangeswaran R, Anthony Lai FA, Wojcikiewicz R \& Carroll J 1998 Expression of inositol 1,4,5-trisphosphate receptors in mouse oocytes and early embryos: the Type I isoform is upregulated in oocytes and downregulated after fertilization. Developmental Biology 203 451-461. (https://doi. org/10.1006/dbio.1998.9071)

Parys JB, de Smedt H, Missiaen L, Bootman MD, Sienaert I \& Casteels R 1995 Rat basophilic leukemia cells as model system for inositol 1,4,5-trisphosphate receptor IV, a receptor of the type II family: functional comparison and immunological detection. Cell Calcium 17 239-249. (https://doi.org/10.1016/0143-4160(95)90070-5)

Rose B \& Loewenstein WR 1975 Permeability of cell junction depends on local cytoplasmic calcium activity. Nature 254 250-252. (https://doi. org/10.1038/254250a0)

Sauerbrun-Cutler MT, Vega M, Keltz M \& McGovern PG 2015 In vitro maturation and its role in clinical assisted reproductive technology. Obstetrical and Gynecological Survey 70 45-57. (https://doi. org/10.1097/OGX.0000000000000150)

Saunders CM, Larman MG, Parrington J, Cox LJ, Royse J, Blayney LM, Swann K \& Lai FA 2002 PLC zeta: a sperm-specific trigger of $\mathrm{Ca}(2+)$ oscillations in eggs and embryo development. Development 129 3533-3544.

Shoji S, Yoshida N, Amanai M, Ohgishi M, Fukui T, Fujimoto S, Nakano Y, Kajikawa E \& Perry AC 2006 Mammalian Emi2 mediates cytostatic arrest and transduces the signal for meiotic exit via Cdc20. EMBO Journal 25 834-845. (https://doi.org/10.1038/sj.emboj.7600953)

Sun L, Haun S, Jones RC, Edmondson RD \& Machaca K 2009 Kinasedependent regulation of inositol 1,4,5-trisphosphate-dependent $\mathrm{Ca} 2+$ release during oocyte maturation. Journal of Biological Chemistry 284 20184-20196. (https://doi.org/10.1074/jbc.M109.004515)

Swann K \& Lai FA 2013 PLC $\zeta$ and the initiation of $\mathrm{Ca}(2+)$ oscillations in fertilizing mammalian eggs. Cell Calcium 53 55-62. (https://doi. org/10.1016/j.ceca.2012.11.001)

Takahashi T, Saito H, Hiroi M, Doi K \& Takahashi E 2000 Effects of aging on inositol 1,4,5-triphosphate-induced $\mathrm{Ca} 2+$ release in unfertilized mouse oocytes. Molecular Reproduction and Development 55 299-306. (https://doi.org/10.1002/(SICI)1098-2795(200003)55:3<299::AIDMRD8>3.0.CO;2-G)
Takahashi T, Takahashi E, Igarashi H, Tezuka N \& Kurachi H 2003 Impact of oxidative stress in aged mouse oocytes on calcium oscillations at fertilization. Molecular Reproduction and Development 66 143-152. (https://doi.org/10.1002/mrd.10341)

Tan JH, Wang HL, Sun XS, Liu Y, Sui HS \& Zhang J 2009 Chromatin configurations in the germinal vesicle of mammalian oocytes. Molecular Human Reproduction 15 1-9. (https://doi.org/10.1093/molehr/gan069)

Tombes RM, Simerly C, Borisy GG \& Schatten G 1992 Meiosis, egg activation, and nuclear envelope breakdown are differentially reliant on $\mathrm{Ca} 2+$, whereas germinal vesicle breakdown is $\mathrm{Ca} 2+$ independent in the mouse oocyte. Journal of Cell Biology 117 799-811. (https://doi. org/10.1083/jcb.117.4.799)

Tosti E 2006 Calcium ion currents mediating oocyte maturation events. Reproductive Biology and Endocrinology 4 26. (https://doi. org/10.1186/1477-7827-4-26)

Tóth S, Huneau D, Banrezes B \& Ozil JP 2006 Egg activation is the result of calcium signalsummation in the mouse. Reproduction 131 27-34. (https://doi.org/10.1530/rep.1.00764)

van der Kant R \& Neefjes J 2014 Small regulators, major consequences - $\mathrm{Ca}^{2+}$ and cholesterol at the endosome-ER interface. Journal of Cell Science 127 929-938. (https://doi.org/10.1242/jcs.137539)

Wakai T \& Fissore RA 2019 Constitutive IP3R1-mediated Ca2+ release reduces $\mathrm{Ca} 2+$ store content and stimulates mitochondrial metabolism in mouse GV oocytes. Journal of Cell Science 132. (https://doi.org/10.1242/ jcs.225441)

Wakai T, Vanderheyden V, Yoon SY, Cheon B, Zhang N, Parys JB \& Fissore RA 2012 Regulation of inositol 1,4,5-trisphosphate receptor function during mouse oocyte maturation. Journal of Cellular Physiology 227 705-717. (https://doi.org/10.1002/jcp.22778)

Wakai T, Zhang N, Vangheluwe P \& Fissore RA 2013 Regulation of endoplasmic reticulum $\mathrm{Ca}(2+)$ oscillations in mammalian eggs. Journal of Cell Science 126 5714-5724. (https://doi.org/10.1242/ jcs.136549)

Wickramasinghe D, Ebert KM \& Albertini DF 1991 Meiotic competence acquisition is associated with the appearance of $\mathrm{M}$-phase characteristics in growing mouse oocytes. Developmental Biology 143 162-172. (https://doi.org/10.1016/0012-1606(91)90063-9)

Yoda A, Oda S, Shikano T, Kouchi Z, Awaji T, Shirakawa H, Kinoshita K \& Miyazaki S 2004 Ca2+ oscillation-inducing phospholipase C zeta expressed in mouse eggs is accumulated to the pronucleus during egg activation. Developmental Biology 268 245-257. (https://doi. org/10.1016/j.ydbio.2003.12.028)

Yurttas P, Vitale AM, Fitzhenry RJ, Cohen-Gould L, Wu W, Gossen JA \& Coonrod SA 2008 Role for PADI6 and the cytoplasmic lattices in ribosomal storage in oocytes and translational control in the early mouse embryo. Development 135 2627-2636. (https://doi.org/10.1242/ dev.016329)

Zhang N, Yoon SY, Parys JB \& Fissore RA 2015 Effect of M-phase kinase phosphorylations on type 1 inositol 1,4,5-trisphosphate receptormediated Ca2+ responses in mouse eggs. Cell Calcium 58 476-488. (https://doi.org/10.1016/j.ceca.2015.07.004)

Zuccotti M, Piccinelli A, Giorgi Rossi P, Garagna S \& Redi CA 1995 Chromatin organization during mouse oocyte growth. Molecular Reproduction and Development 41 479-485. (https://doi.org/10.1002/ mrd.1080410410)

Zuccotti M, Ponce RH, Boiani M, Guizzardi S, Govoni P, Scandroglio R, Garagna S \& Redi CA 2002 The analysis of chromatin organisation allows selection of mouse antral oocytes competent for development to blastocyst. Zygote $\mathbf{1 0}$ 73-78. (https://doi.org/10.1017/ S0967199402002101)

Received 11 December 2018

First decision 7 January 2019

Revised manuscript received 8 February 2019

Accepted 26 February 2019 